Statistics of Extremes

By Prof. E. J. Gumbel. Pp. $x x+375$. (New York : Columbia University Press; London: Oxford University Press, 1958.) 120s. net.

$\mathrm{T}$ HE theory of extreme values is concerned with the probability distribution of the largest values encountered in samples of finite size : it has many applications including the occurrence of floods and droughts and the breakdown of materials, such as aircraft components, subject to varying stresses and strains.

Prof. Gumbel has for many years been a leading authority on the subject and his book is likely to become a standard work. Although the book appears to contain little essentially new theory, it collects and elaborates previous work hitherto widely scattered in the statistical literature and contains many tables and graphs of functions occurring in the theory. There is an excellent bibliography containing references to both theoretical and applied work. The text includes numerous exercises for the reader. The eight chapter headings are "Aims and Tools", "Order Statistics and Their Exceedances", "Exact Distribution of Extremes", "Analytical Study of Extremes", "The First Asymptotic Distribution", "Uses of the First Asymptote", "The Second and Third Asymptotes" and "The Range".

Although several examples of applications are discussed, this book is not a 'cook-book' of practical methods, but it should prove extremely useful to the statistician required to analyse extreme-value data. The scientist interested in practical applications will need considerable mathematical and statistical experience to follow the rather concentrated and sophisticated mathematics. In particular he may find difficulty in assessing the practical importance of some of the concepts defined and some of the results derived.

The high cost probably makes this book one for the library rather than for the individual and is presumably due to the large number of graphs it contains.

R. N. CURNOW

\section{The Chemistry of Natural Products}

Vol. 1. The Alkaloids. By K. W. Bentley. Pp. vii + 237. 4 dollars. Vol. 2. Mono- and Sesquiterpenoids. By P. de Mayo. Pp. vii +320. 52s. Vol. 3. The Higher Terpenoids. By P. de Mayo. Pp. vii +239 . 42s. (New York: Interscience Publishers, Inc.; London: Interscience Publishers, Ltd., 1959.)

$\mathrm{B}$ OOKS on natural products have in the past usually suffered from several disadvantages: they have tended to consist of catalogues, and quite frequently have been written by specialists who had rather lost contact with the general body of advancing science and did not emphasize relations to chemistry in general. A very welcome tendency is for young and enthusiastic men, themselves deeply involved in the subject from the research side, to summarize fields of research in what might be described as super $\mathrm{Ph}$.D. theses. The advantage of their approach is that it is fresh, but nevertheless authoritative, and that their acquaintance with modern theories of reaction mechanisms and biosynthetic theories enables them to produce monographs which are of general interest and general importance. The three books in the title are in this class. They should interest and inform advanced undergraduates, research students and university or college teachers who have not had the time to keep up with the literature. They are not perhaps exhaustive enough for research specialists but should provide useful starting-points for research. The general resemblance to theses, particularly in the formulae, will not please lovers of beautiful books, but presumably they would otherwise have been more expensive. They can be heartily recommended to all who are interested in rapidly advancing fields whether as teachers, students or research workers.

A. J. BIRCH

The Psychology of Social Class

By Maurice Halbwachs. Translated by Claire Delavenay. (Heinemann Books on Sociology.) Pp. xvii + 142. (London: William Heinemann, Ltd., 1958.) 16s, net.

AAURICE HALBWACHS was a French socio1 logist who learnt in his early manhood to share the liberalism and democratic principles which deeply influenced the generation destroyed by the First World War. It was his inheritance of these principles which led to his own death in Buchenwald in 1945, and it is for this that he must be remembered and honoured. His work as a sociologist is typical of a transitional age, and his writings on the sociology of class distinctions and behaviour are of interest in so far as they illustrate the swing-over from the oversystematic thinking of the sociologists of the nine. teenth century to the empiricism which appears to be gaining ground in the second half of the twentieth.

It is evident, however, that Halbwachs had not shaken off his attachment to abstract theories even as late as 1938, when he wrote this book; moreover, it is also evident that he had not mastered the diffi. culties of basing generalizations on evidence in such a way that a framework of truly scientific theory might be constructed. On one hand, Halbwachs was unable to resist the temptation to quote from the works of the great classical philosophers, as well as the theorists of his own age, such as Durkheim and Weber. On the other, he was only too ready to present a mass of often undigested information derived from such sources as the German Government's survey of working-class budgets, carried out in 1927-28. What was lacking in his work was a serious attempt to relate the evidence to the generalizations founded on it.

T. S. Srmey

\section{Toward a Systematic Pragmatics}

By R. M. Martin. (Studies in Logic and the Foundations of Mathematics.) Pp. xv +107. (Amsterdam : North-Holland Publishing Company, 1959.) $24 s$.

r.HIS recent addition to "Studies and Foundations" is a valuable monograph in a highly specialist field, and adds lustre to that distinguished series. The main discussion concerns type-theoretical systems, pragmatical meta-language, analytic truth and absolute intensions. These subjects are introduced by a preliminary chapter on the nature of pragmatics. In brief, language-systems can be either syntactical, semantical or pragmatical, and this corresponds to the order of abstraction.

Thus, in syntax, it is only the signs or expressions (and their inter-relations) which are interesting. In semantics, the objects which the signs denote come into the picture. Finally, in pragmatics, the speakers or users of the language are involved. The author's point of view is wholly extensional, whereas that of Carnap is intensional. The power of extensional meta-languages to cover a large part of mathematics, physics, and even biology, is clearly advantageous. F. I. G. RawLINS 